\title{
Publisher Correction: Craters, boulders and regolith of (101955) Bennu indicative of an old and dynamic surface
}

K. J. Walsh (D, E. R. Jawin, R.-L. Ballouz D, O. S. Barnouin (D), E. B. Bierhaus, H. C. Connolly Jr (D), J. L. Molaro, T. J. McCoy, M. Delbo', C. M. Hartzell ID, M. Pajola DD, S. R. Schwartz, D. Trang, E. Asphaug, K. J. Becker (D), C. B. Beddingfield, C. A. Bennett, W. F. Bottke, K. N. Burke ID, B. C. Clark, M. G. Daly D, D. N. DellaGiustina (D), J. P. Dworkin (D), C. M. Elder, D. R. Golish, A. R. Hildebrand, R. Malhotra, J. Marshall, P. Michel ID, M. C. Nolan D, M. E. Perry, B. Rizk D., A. Ryan, S. A. Sandford, D. J. Scheeres (D), H. C. M. Susorney, F. Thuillet, D. S. Lauretta and The OSIRIS-REx Team

Correction to: Nature Geoscience https://doi.org/10.1038/s41561-019-0326-6, published online 19 March 2019.

In the version of this Article originally published, in the sentence "There are three identified boulders with long axes exceeding $40 \mathrm{~m}$ and

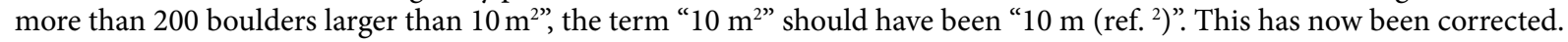

Published online: 4 April 2019

https://doi.org/10.1038/s41561-019-0360-4 